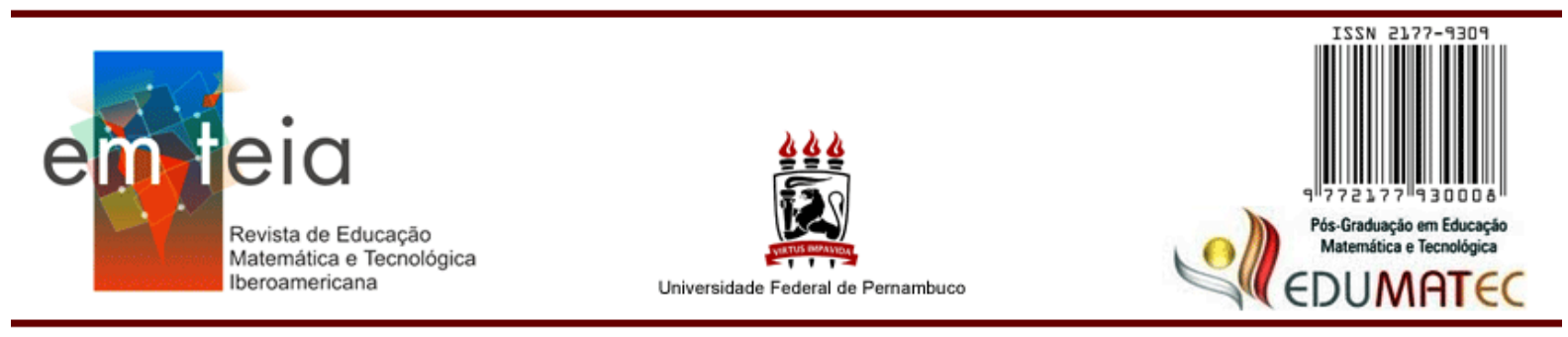

\title{
A IGUALDADE NA AULA DE MATEMÁTICA DA EDUCAÇÃO INFANTIL: POR QUE DEVEMOS FICAR ATENTOS AO USAR ESSE SINAL?
}

\section{EQUALITY IN THE EARLY CHILDHOOD MATHEMATICS CLASS: WHAT SHOULD WE BE AWARE OF WHEN USING THIS SIGN?}

\author{
Ana Virginia de Almeida Luna \\ Doutora em Ensino, Filosofia e História da Educação \\ Universidade Estadual de Feira de Santana - UEFS - BA - Brasil \\ avaluna@uefs.br \\ https://orcid.org/0000-0002-0106-487X \\ Vera Lucia Merlini \\ Doutora em Educação Matemática \\ Universidade Estadual de Santa Cruz - UESC - BA - Brasil \\ vlmerlini@uesc.br \\ https://orcid.org/0000-0001-9784-3546 \\ Ângela Ateone Batista do Carmo Ferreira \\ Mestre em Educação \\ Secretaria Municipal de Educação de Teofilândia - BA - Brasil \\ angelaateone2@gmail.com \\ https://orcid.org/0000-0003-2930-7981
}

\section{Resumo}

O presente artigo tem por objetivo analisar os textos do discurso instrucional de igualdade que foram operados por uma professora no processo de recontextualização do curso de formação continuada em Early Algebra na sua sala de aula da educação infantil. E, desse modo, possibilitar que outros profissionais da Educação Infantil tenham acesso a esse estudo, a fim de que possam dialogar, levar para suas salas de aula e socializar experiências, assim como estabelecer uma interlocução com outros pares e pesquisadores. A pesquisa foi desenvolvida por meio de uma abordagem qualitativa, com a utilização do modelo de investigação da Linguagem de Descrição, desenvolvido pelo sociólogo Basil Bernstein, com o qual discutimos como foi realizado o deslocamento do texto do discurso de igualdade de uma Formação sobre Early Algebra em sala de aula. Para isso foram observadas duas propostas de atividades da Professora Juliana. Os resultados deste estudo evidenciam que é possível trabalhar com noções de equivalência desde a educação infantil, pois a professora realizou atividades de cunho algébrico, com os seus estudantes, favorecendo que eles estabelecessem relação com o conceito de equivalência por 
meio das interações nas brincadeiras e nas demais atividades propostas. Nesses contextos as crianças se aproximaram dos textos do discurso da igualdade.

Palavras-Chave: Formação de Professor. Educação Infantil. Early Algebra. Igualdade.

\begin{abstract}
This article aims to analyze the texts of the instructional discourse of equality that were operated by a teacher in the process of recontextualizing the continuing education course in Early Algebra in her Early Childhood Education classroom. And, in this way, enable other professionals in Early Childhood Education to have access to this study, so that they can dialogue, take it to their classrooms and socialize experiences, as well as establish a dialogue with other peers and researchers. The research was developed through a qualitative approach, using the research model of the Language of Description, developed by the sociologist Basil Bernstein, with which we discussed how the displacement of the text of the equality discourse of a Formation on Early Algebra was carried out. in the classroom. For this, two proposals for activities by Teacher Juliana were observed. The results of this study show that it is possible to work with notions of equivalence from Early Childhood Education, as the teacher carried out algebraic activities with her students, favoring them to establish a relationship with the concept of equivalence through interactions in games and in other proposed activities. In these contexts, children approached the texts of the equality discourse.
\end{abstract}

Keywords: Teacher Education. Early Childhood Education. Early Algebra, Equality.

\title{
Introdução
}

Ao decidirmos pela escrita deste estudo, fomos em busca de trabalhos relacionados à Educação Infantil e à Early Algebra. Embora pesquisas com foco em Early Algebra sejam relativamente novas em relação a outros contextos, encontramos estudos pautados tanto no que diz respeito ao ensino, ênfase no professor, quanto à aprendizagem, foco no estudante. Ainda que tenhamos encontrado estudos voltados para a Educação Infantil, a maioria deles diz respeito aos Anos Iniciais do Ensino Fundamental (BLANTON; KAPUT, 2005; LUNA; SOUZA, 2013; LUNA; SOUZA; SOUZA, 2015; MERLINI; MAGINA; TEIXEIRA, 2018; FERREIRA; RIBEIRO; PONTE, 2021).

No que se refere à Educação Infantil, as pesquisas encontradas foram no âmbito internacional, ainda que poucas pautadas explicitamente na Early Algebra. Algebra (SCHLIEMANN; CARRAHER; BRIZUELA, 2011). E, na esfera nacional, não encontramos estudos com este tema, exceto o iniciado em nossos grupos de pesquisa (LUNA; MERLINI; SILVA, 2020; FERREIRA, 2020; VIEIRA; MAGINA; LUNA, 2021). Sabemos que não cabe aqui afirmarmos que pesquisas nesse nível escolar inexistem sobre Early Algebra, mas sim que, se existem, elas são escassas.

Em 2006, a National Academy of Sciences (NAS), nos Estados Unidos, promoveu um congresso no qual reuniram-se pesquisadores para pensar o ensino de Álgebra nos diversos 
níveis de escolaridade, sendo que a Early Algebra esteve voltada para o que eles denominam por PreK-8, o que equivale para nós ao período que se estende da pré-escola até o final do Ensino Fundamental. Desde a primeira década deste século, podemos encontrar em documentos oficiais internacionais a abordagem de conceitos algébricos desde os Anos Iniciais do Ensino Fundamental e, em particular, as primeiras implementações da inclusão da álgebra na Educação Infantil. Um destes documentos, por exemplo, é o $\operatorname{NCTM}^{1}$ (2007) National Council of Teachers of Mathematics.

Buscamos, também, nos documentos oficiais nacionais que orientam e regularizam a Educação Infantil e eles não trazem explicitamente o quê e como os conceitos matemáticos devem e podem ser abordados nessa faixa etária. As Diretrizes Curriculares Nacionais Gerais da Educação Básica (BRASIL, 2013), que contemplam a Educação Infantil, apresentam como item 3, "Proposta Pedagógica e seus Objetivos", uma "Aprendizagem permeada pelo desenvolvimento das habilidades e competências por meio da vivência, da experimentação e resolução de situações-problema, para que esta desenvolva seus princípios para sua formação integral" (BRASIL, 2013, p. 71), embora não especifique o que seriam essas habilidades e competências. Na BNCC (BRASIL, 2017), nosso documento oficial mais recente, a álgebra só é mencionada explicitamente a partir dos Anos Iniciais do Ensino Fundamental.

Adicionado a esse cenário, temos os cursos de formação inicial da Licenciatura em Pedagogia, que se concentram em metodologias de ensino em detrimento aos conceitos matemáticos, em geral, de forma genérica pela carga horária curta. Além disso, os programas de formação continuada realizados pela última gestão federal, que teve como objetivo fortalecer ações de formação e acompanhamento dos professores do ciclo inicial, $1^{\circ}$ ao $3^{\circ}$ ano, e do ciclo complementar, $4^{\circ}$ e $5^{\circ}$ anos, Programa Nacional de Alfabetização na Idade Certa (PNAIC) ${ }^{2}$, na perspectiva de alfabetizar todas as crianças, no máximo, até os 8 (oito) anos de idade, ainda assim, esses programas só atendaram aos professores dos Anos Iniciais do Ensino Fundamental, não contemplaram os que atuam na Educação Infantil.

Para além dessas formações continuadas, propostas pelo poder público, há também aquelas desenvolvidas por professores universitários, a partir de projetos de pesquisa e extensão, além dos grupos de estudos ligados aos programas de pós-graduação. Essas formações são importantes na medida em que há interlocução entre a teoria (universidade) e a

\footnotetext{
${ }^{1}$ O NCTM é uma associação profissional, sem fins lucrativos. Além disso, é a principal organização para professores de Matemática desde K-12 (Educação Infantil até o Ensino Médio).

${ }^{2}$ O PNAIC foi instituído pela Portaria ${ }^{\circ} 867$, de 4 de julho de 2012.
} 
prática (professores da Educação Básica). No entanto, o que predomina ainda são aquelas voltadas para, principalmente, os professores dos Anos Iniciais e algumas para os Anos Finais no Ensino Fundamental.

Diante desse quadro, observamos que há uma lacuna e que é preciso discutir a esse respeito, uma vez que a Educação Infantil é tida como obrigatória e conceitos matemáticos já são apresentados às crianças. Tais conceitos podem ser relacionados pelas crianças por meio de suas vivências cotidianas, em interações e brincadeiras que sugerem alguma articulação com o conhecimento matemático. Por exemplo, na confecção de um colar de bolinhas com duas cores, sendo que a cada três bolinhas ela muda de cor. Nesta situação temos uma sequência repetitiva de dois grupos, sendo que cada uma deles tem três elementos.

Esse artigo é um recorte de um projeto de pesquisa que previa uma proposta de formação professores dos Anos Iniciais do Ensino Fundamental e da Educação Infantil, cujo propósito foi investigar sobre a Early Algebra. Entendemos por Early Algebra o estudo do desenvolvimento do raciocínio algébrico desde a Educação Infantil e Anos Iniciais do Ensino Fundamental.

Na presente investigação o nosso objetivo foi analisar os textos do discurso instrucional de igualdade que foram operados por uma professora no processo de recontextualização do curso de formação continuada em Early Algebra na sua sala da Educação Infantil.

\section{O sinal de igualdade na aula de Matemática na Educação Infantil}

Antes de iniciarmos a discussão a respeito do sinal de igualdade, é importante partirmos do que é o raciocínio algébrico. De acordo com Blanton e Kaput (2005), o raciocínio algébrico pode assumir várias formas, incluindo: i) o uso de aritmética como um domínio para expressar e formalizar generalizações (aritmética generalizada); ii) generalizar padrões numéricos para descrever relações funcionais (pensamento funcional); iii) modelagem como um domínio para expressar e formalizar generalizações; e iv) generalizar sobre sistemas matemáticos abstraídos de cálculos e relações.

Para o presente estudo, destacamos a primeira e a quarta forma apresentadas, ainda que sem ênfase em formalizações. Analisando a primeira, o uso de aritmética como um domínio para expressar e favorecer possíveis generalizações, entendemos que as crianças desde pequenas podem estabelecer relações entre as operações e propriedade comutativa de adição ou propriedade do elemento neutro (de zero), ou compreensão da igualdade como uma relação entre as quantidades, tanto discretas como contínuas. E, na quarta, generalizar sobre sistemas 
matemáticos advindos de cálculos e relações, compreendemos que a generalização pode ser expressada a partir da manipulação feita com objetos.

De acordo com Ponte, Branco e Matos (2009), o sinal da igualdade pode ser entendido a partir de três significados, a saber: a ideia operacional, de equivalência e relacional. O significado operacional envolve a aritmética, em que a ênfase está no uso do sinal da igualdade para encontrar o resultado das operações. Segundo Behr, Erlwanger e Nichols (1980), a tarefa em que é solicitado que as crianças armem e efetuem as operações, desde a Educação Infantil, induzem-nas a identificar o sinal de igualdade apenas como uma instrução para fazerem algo do lado esquerdo e apresentarem a resposta do lado direito. Quanto ao significado de equivalência, o sinal de igualdade está relacionado à noção de equilíbrio e ao conceito de equação. Na literatura, a balança é um material manipulável bastante utilizado para desenvolver o significado de equivalência (LESSA, 1996).

Por fim, o último significado, o relacional, é uma representação de uma igualdade de expressões, em uma relação funcional. Para Carpenter et al. (2005), oportunizar o uso do pensamento relacional, desde o início da escolaridade, ao trabalhar com expressões aritméticas, favorece a integração das relações e propriedades aritméticas em atividades matemáticas. Além disso, possibilita que o conhecimento e as habilidades que os estudantes desenvolvem durante o ensino fundamental estejam mais alinhados com os conceitos e as habilidades que são necessários para a aprendizagem da algébrica (CARPENTER et al., 2005).

Ao considerar os estudos de Carpenter, Franke e Levi (2003) no que se refere às propostas de atividades envolvendo o sinal de igualdade, deveriam ser evitadas três tipos de situações. A primeira relaciona-se à correspondência de nomes de pessoas e idades ou ainda, nomes e número de pontos em um jogo, por exemplo, Natália $=10$, Lucas $=9$. Para Carpenter, Franke e Levi (2003, p. 21), o sinal de igualdade deveria ser reservado para mostrar a relação entre números ou expressões numéricas.

A segunda situação a ser evitada refere-se às Figuras $1 \mathrm{e} 2$. Ainda conforme Carpenter, Franke e Levi (2003), a quantidade de tartarugas da coleção representada na Figura 1 é 6, mas a coleção em si, neste caso das tartarugas, não é igual a um número. 
Figura 1- Designando o número de objetos em uma coleção

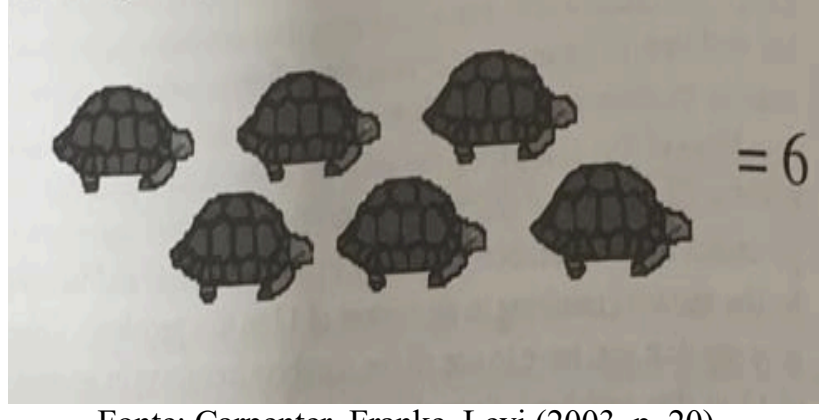

Fonte: Carpenter, Franke, Levi (2003, p. 20).

Isso ocorre também na Figura 2, pois o número de objetos em uma coleção não é igual a outro grupo, ainda que sejam do mesmo tipo (figuras de coelhos).

Figura 2 - Usando igualdade entre duas figuras

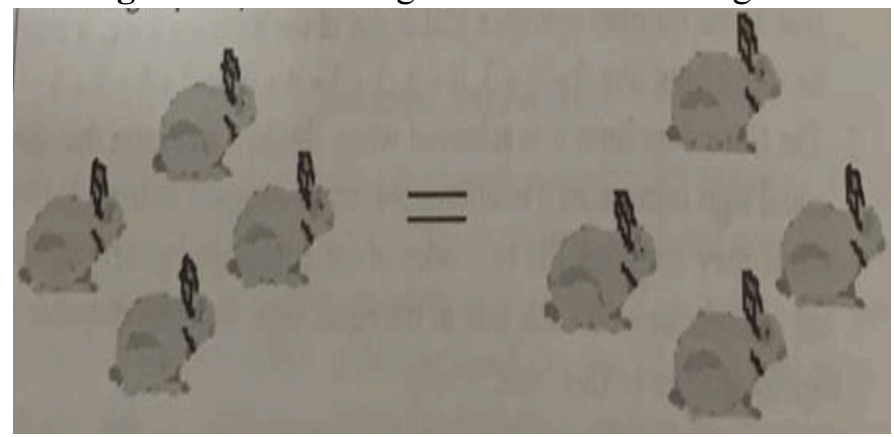

Fonte: Carpenter, Franke, Levi (2003, p. 20).

A terceira situação a ser evitada é o uso da igualdade para representar uma sequência de cálculos. Isso pode ser observado, por exemplo, na resolução de uma situação-problema, em que uma criança produz a sua estratégia da seguinte forma: $20+15=35+5=40+4=44$. Em casos como na Figura 3, devem ser criadas oportunidades para que os estudantes possam começar a analisar e produzir a sua estratégia, utilizando a igualdade de forma adequada

Figura 3 - Usando igualdade com ênfase em cada etapa da estratégia

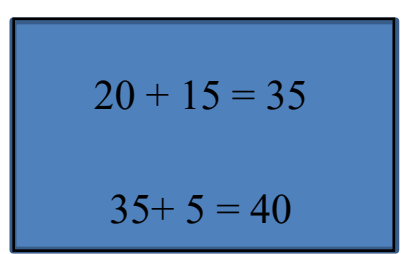

Fonte: As autoras

Analisando as situações possíveis de serem evitadas, entende-se que, ao descartá-las enquanto prática na Educação Matemática, os estudantes poderão, desde o início da sua escolaridade, ter a oportunidade de estabelecer relações com os números. Carpenter Franke e 
Levi (2003) afirmam que, na aprendizagem da aritmética e da álgebra, faz-se necessário reconhecer o sinal de igualdade e utilizá-lo para desenvolver o pensamento relacional e calcular um resultado. Por outro lado, para esses autores, quando os estudantes compreendem somente a noção operacional do sinal de igualdade, se limitam apenas a um processo de memorização de um conjunto de regras. Na verdade, esse pensamento relacional deverá ser desenvolvido a partir de princípio da igualdade, dentre eles o aditivo e o multiplicativo.

O princípio aditivo da igualdade se dá ao adicionar ou subtrair um mesmo número nos dois membros de uma igualdade, obtendo outra sentença que ainda é uma igualdade (CARPENTER; FRANKE; LEVI, 2003). Para visualizarmos uma igualdade, vamos observar a balança de dois pratos da Figura 4, que tem a seguinte relação: o peso ${ }^{3}$ de um pote de massa de modelar amarela, que pesa $200 \mathrm{~g}$, corresponde ao peso de dois potes de massa de modelar vermelha, que pesa $100 \mathrm{~g}$ cada.

Figura 4 - Balança equilibrada com potes de massa de modelar

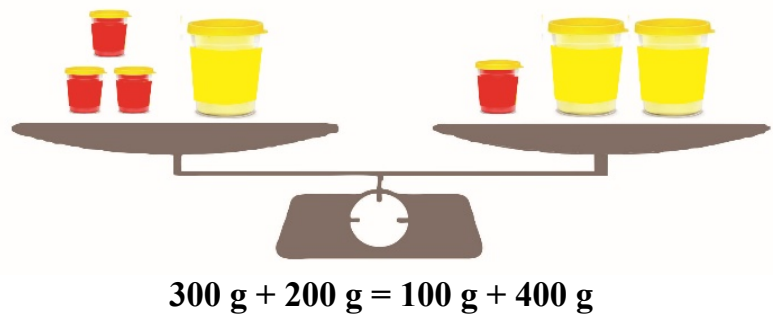

Fonte: As autoras

$\mathrm{Na}$ Figura 4 temos uma balança equilibrada, pois a massa correspondente aos potes de massa de modelar que há no prato da esquerda é a mesma no prato da direita, lembrando que os potes massa de modelar amarela têm o dobro da capacidade dos potes de massa de modelar vermelha.

\footnotetext{
${ }^{3}$ Massa é a quantidade de matéria que um corpo possui, e mantém-se sempre a mesma, qualquer que seja o local onde o corpo se encontre. Já o peso representa a força com que a terra atrai um corpo, e está relacionado à força da gravidade (peso = massa X aceleração da gravidade), por isso apresenta variação, conforme a localidade em que o corpo se encontra; quanto mais próximo do centro da Terra, maior será o peso de um corpo (TOLEDO, 1997).
} 
Agora, se pegarmos essa mesma balança da Figura 4 e colocarmos dois potes de massa de modelar vermelha nos dois pratos, o que irá acontecer?

Figura 5 - Balança e o Princípio aditivo da igualdade

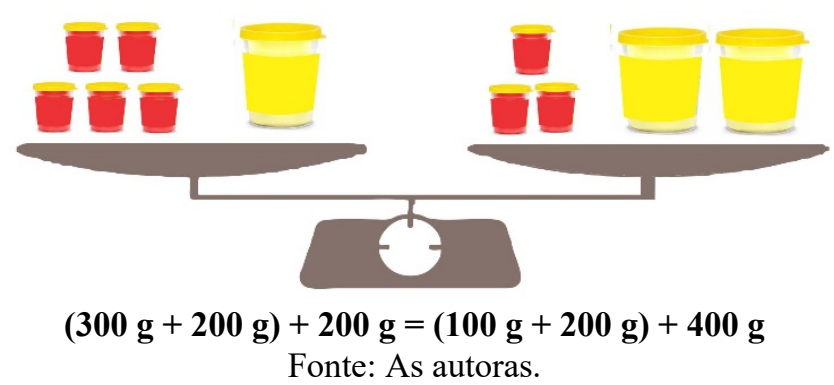

Para que a balança continue em equilíbrio, a mesma quantidade de massa (dois potes de massa de modelar vermelha) que colocamos em um prato deveremos colocar no outro. Adicionando dois potes de massa de modelar vermelha em cada um dos pratos da balança da Figura 4, o equilíbrio manteve-se, como podemos observar na balança da Figura 5.

O princípio multiplicativo da igualdade dar-se-á ao multiplicar ou dividir por um mesmo número (diferente de zero) os dois membros de uma igualdade, obtendo-se uma nova sentença que ainda é uma igualdade. Triplicando a quantidade de potes de massa de modelar da balança da esquerda obtemos como resposta a balança da direita, conforme a Figura 6.

Figura 6 - Balança e o Princípio multiplicativo da igualdade

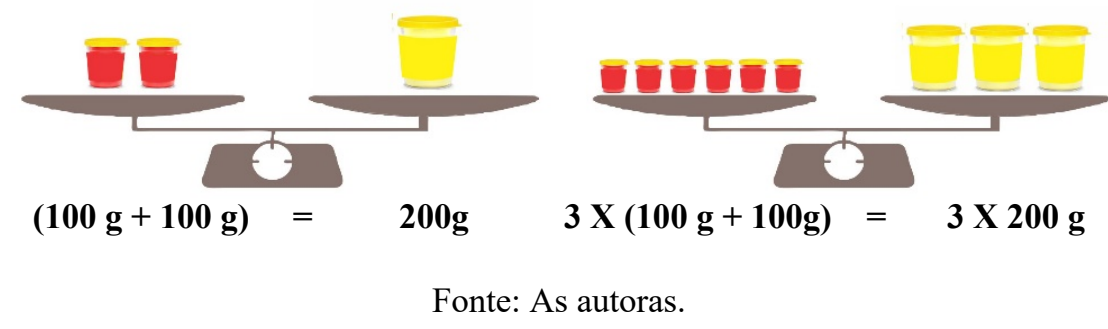

A balança da esquerda está em equilíbrio, uma vez que dois potes de massa de modelar vermelha correspondem a um pote de massa de modelar amarela. Ao triplicar a quantidade de massa dos dois pratos da balança da esquerda o equilíbrio manteve-se, como observamos na balança da direita da Figura 6.

Os princípios aditivo e multiplicativo da equivalência citados e explicitados a partir do uso da balança e da representação da linguagem matemática estão voltados para a compreensão 
pelo professor, na leitura desse artigo, por entendermos que no processo de ensino aprendizagem é relevante que o docente tenha domínio específico do objeto que está sendo discutido em sala de aula. Desse modo, não se caracteriza, necessariamente, como um exemplo didático para ser utilizado com os estudantes da Educação Infantil.

\section{Os textos produzidos na prática pedagógica e o discurso instrucional de álgebra}

A nossa compreensão neste estudo em relação à expressão texto é de "qualquer comunicação falada, escrita, visual, espacial" produzida por uma certa pessoa (BERNSTEIN, 2003). Desta forma, corroboramos a visão de Luna, Barbosa e Morgan (2011) de que texto, em termos da comunicação, não deve estar restrito à escrita, mas dizer respeito a qualquer ato comunicativo, seja ele um gesto, um olhar, uma postura corporal ou uma forma de expressão. Em termos bernsteinianos, o texto é legítimo quando é produzido com um significado pertinente ao contexto de uma determinada prática pedagógica (BERNSTEIN, 2003).

Se considerarmos uma sala de aula da educação infantil, por exemplo, a partir dos diferentes textos produzidos pelas crianças e docente, podemos inferir os princípios que regulam esta prática pedagógica. Esta prática, para Bernstein (2000), se constitui em uma relação social, como um condutor cultural, sendo esta relação constituída entre alguém que ensina (ex: docente) e alguém que aprende (ex: estudante). Entre tais práticas pedagógicas para o autor também estão incluídas outras relações como, por exemplo, engenheiros e mestres de obra, arquiteto e engenheiro, médico e paciente.

Para tanto, Bernstein (2003) afirma que o texto torna a forma da relação social visível, possível de ser materializada. Com isto, o autor sinaliza para o fato de que a materialidade dos princípios reguladores da produção textual está impressa na forma e no conteúdo dos próprios textos. Desse ponto de vista, os textos apresentados por professores e estudantes na tradição da Matemática Escolar comunicam-nos os modos como podem acontecer a relação entre docente e estudante, a relação dos estudantes entre si e a relação da Matemática com as outras disciplinas (LUNA, 2012).

De acordo com Bernstein (2003), a produção do texto legítimo é regulada pelo discurso pedagógico. Tal discurso, para este autor, é um conjunto de princípios para a apropriação de outros textos e para dispô-los em uma relação mútua especial, para a sua transmissão e aquisição seletivas em um determinado contexto (BERNSTEIN, 2003).

Seguem exemplos de dois casos em que o discurso pedagógico pode ser observado, ambos envolvendo situações-problema de Early Algebra, propostas por duas professoras, 
referente à igualdade para crianças de 5 anos. A primeira delas consiste no uso de material manipulável (cartas do Jogo da Memória), depois de se trabalhar com a adição das duas faces de dois dados. Trata-se de um Jogo da Memória que contém 14 cartas, nas quais estão registradas 14 das 21 possibilidades de adição das faces dos dados. Essas 14 cartas foram elaboradas de tal forma que somente uma dupla delas resulta na mesma soma, como observamos na Figura 7.

Figura 7 - Jogo da Memória - a igualdade com significado relacional

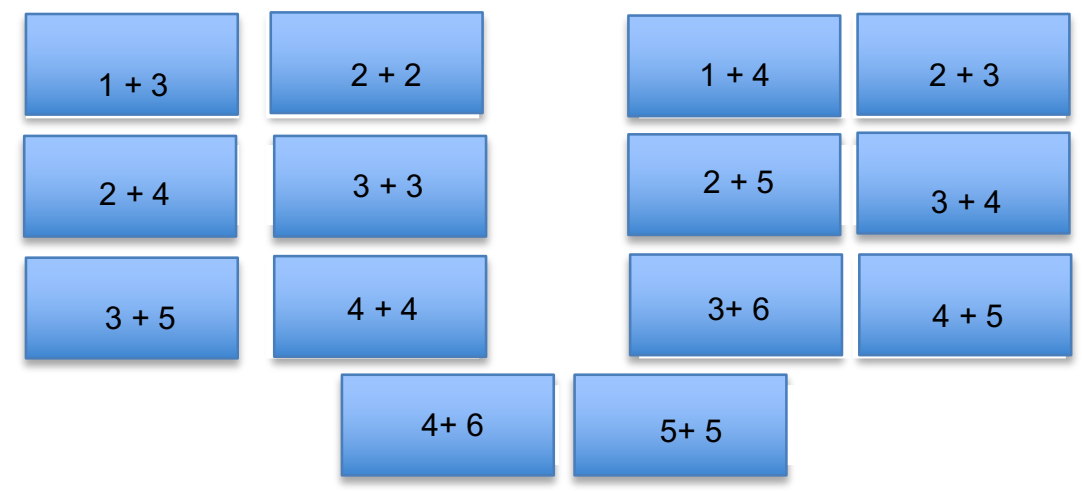

Fonte: As autoras.

Essa atividade do Jogo da Memória tem por objetivo estabelecer a equivalência entre duas expressões matemáticas e apresentar o significado do sinal de igual como sendo relacional, ou seja, ao virar a carta com a expressão $1+3$ só poderá fazer par com a carta cuja expressão é $2+2$, por exemplo, assim teremos $1+3=2+2$. Os números do primeiro membro da igualdade não são os mesmos do segundo membro, no entanto, a soma é a mesma e, portanto, estão relacionados (PONTE; BRANCO; MATOS, 2009).

A atividade da segunda professora também está atrelada ao uso do sinal de igual. Essa atividade consiste em ligar as adições da esquerda com os resultados dispostos à direita, conforme observamos na Figura 8.

Figura 8 - Resolva e ligue - a igualdade com significado operacional

$$
\begin{array}{cc}
4+5 & 11 \\
6+6 & 3 \\
2+6 & 9 \\
1+2 & 8 \\
5+6 & 12
\end{array} \text { Fonte: As autoras }
$$

Tal atividade tem por objetivo estabelecer a equivalência entre a adição de duas parcelas e seu respectivo resultado. Nesse caso, o sinal de igual tem outro significado, qual seja, o operacional. Situações-problema como estas fazem com que os estudantes concebam o sinal de 
igual como um indicativo de realizar a operação e dar o resultado. Na verdade, a expressão matemática 4+5=9 é lida como quatro mais cinco dá nove (BEHR; ERLWANGER; NICHOLS, 1980; STACEY; MACGREGOR, 1997).

Nas duas propostas, o texto legítimo diz respeito ao mesmo objeto matemático: equivalência. A mudança está somente nas referências da tarefa e nos processos em que os estudantes são submetidos (LUNA, 2012). Podemos perceber algo comum aos dois casos, relacionado à especificidade do discurso da matemática escolar. Por outro lado, "os exemplos mencionados mostram que é possível identificar variabilidade em seus princípios" (LUNA, 2012, p. 128).

De acordo com Bernstein (2000), o discurso pedagógico é um conjunto de princípios para apropriar outros textos e dispô-los numa relação mútua especial, com vistas à sua transmissão e aquisição seletivas em um determinado contexto (BERNSTEIN, 2003). Este discurso é constituído por dois discursos, a saber, pelo discurso instrucional e pelo discurso regulativo. O primeiro diz respeito aos conhecimentos mais específicos (o quê e o como transmiti-los). Quanto ao segundo, este se refere à ordem social, às normas de conduta, à transmissão de valores. Esse princípio é determinante na ordem interna do discurso da instrução na prática pedagógica (BERNSTEIN, 2003).

Nesse processo, a recontextualização refere-se ao deslocamento de textos em diferentes contextos de produção e reprodução, gerando novos sentidos para os discursos mediados pelas relações de poder e pela regulação de ordem social (BERNSTEIN, 2000). No presente estudo, a constituição do discurso pedagógico ocorrerá a partir da recontextualização do discurso instrucional de igualdade embutido no discurso regulativo, ou seja, quando a professora operar o deslocamento de textos do discurso instrucional de igualdade embutido no discurso regulativo - que foram produzidos no Curso de Extensão em Early Algebra - e reposicioná-los para o contexto da sua sala de aula

\section{Caminhos percorridos pelo estudo}

O presente estudo foi desenvolvido a partir de uma abordagem qualitativa que busca compreender os significados dos aspectos da vida social, dificilmente quantificáveis, apresentados no fenômeno investigado (DENZIN; LINCOLN, 2006; CRESWELL, 1998).

Tal estudo está vinculado ao projeto de pesquisa "A Early Algebra no Ensino Fundamental: mapeamento e diagnóstico", financiado pela Universidade Estadual de Santa Cruz-UESC, Resolução CONSEPE n $115 / 17$ e ao projeto “A Early Algebra no Ensino 
Fundamental: Mapeamento, Diagnóstico e Formação" aprovado pela Universidade Estadual de Feira de Santana-UEFS, Resolução CONSEPE nº 048/2019. Esta pesquisa teve como objetivo desenvolver, junto a outros estudos, uma formação continuada para professores dos grupos que participaram do diagnóstico sobre a Early Algebra. É um estudo vinculado ao Programa de Pósgraduação em Educação da UEFS, do Núcleo de Estudos em Educação Matemática de Feira de Santana (NEEMFS), em parceria com o Programa de Pós-graduação em Educação em Ciência e Matemática da UESC, do Grupo de Pesquisa Reflexão, Planejamento, Ação Reflexão em Educação Matemática (RePARe em Ed.Mat) da UESC.

Portanto, a pesquisa foi desenvolvida a partir de um curso de formação continuada, com metodologia baseada no ensino híbrido, em que foram disponibilizados oito módulos de estudo, sendo parte deles realizados de forma presencial na Universidade Estadual de Feira de Santana e a outra parte em um ambiente virtual de aprendizagem. Destes, nos módulos VII e VIII foi discutido o conceito de equivalência e, para tanto, foram encaminhadas, via plataforma, orientações de estudo aos participantes a respeito do conceito de equivalência por meio de roteiro de estudo, vídeo, texto e slides com fundamentos teóricos. Essas orientações foram para que os educadores tivessem condições de elaborar em grupo, de acordo com o ano escolar que lecionava, o Relatório de Planejamento de duas propostas de atividades para seus respectivos estudantes.

Foram realizados dois Relatórios de Planejamento em dois encontros diferentes, com duas horas de duração cada, os quais foram desenvolvidos em semanas consecutivas. Posteriormente, as experiências foram socializadas nos encontros presenciais e nos fóruns de discussão, disponibilizados no ambiente virtual.

A colaboradora de nossa pesquisa foi uma das professoras da Educação Infantil que participou da formação. Desde o primeiro encontro de formação continuada, a professora Juliana (nome fictício) mostrou interesse em conhecer a possibilidade de trabalhar com Early Algebra na Educação Infantil e concordou com as visitas da pesquisadora em seu espaço de atuação. A professora é formada em Pedagogia desde 2009, tem mais de uma década de experiência educacional, porém nunca gostou muito da área de Matemática durante sua trajetória estudantil e também não tinha muita segurança para ensinar Álgebra. A escola na qual a professora atuava está localizada no interior da Bahia, é pública municipal conveniada com uma universidade pública e contempla desde o ensino infantil até os anos finais do Ensino Fundamental. Para efeito desse estudo, os textos elaborados e analisados foram coletados, por meio da observação com a gravação de vídeos e do diário de bordo, a partir de dois encontros, com duas aulas cada, ministradas pela professora Juliana, para crianças de quatro anos. 
No processo de análise de dados, utilizamos o modelo sociológico da linguagem de descrição em investigação sociológica de Bernstein (2000), que favorece uma relação dialética entre os conceitos constituídos por uma teoria e os dados empíricos a serem analisados a partir de dois tipos de linguagem: a interna (teoria) e a externa (empiria). A linguagem interna é constituída por uma teoria ou por um conjunto de teorias; a linguagem externa é constituída por proposições e modelos derivados da linguagem interna de descrição (BERNSTEIN, 2000).

\section{Análise da Aula da Professora Juliana}

Para efeito de análise, trouxemos dois excertos referentes às duas aulas da Professora Juliana para discutirmos como ela realizou o deslocamento do texto do discurso de igualdade.

A primeira situação proposta pela Professora teve por objetivo compreender a ideia de igualdade por meio do equilíbrio e da relação entre equivalência com o peso que possui cada objeto, com uso de material manipulativo. Para tanto, ela utilizou o encosto de uma cadeira, uma vara de madeira de aproximadamente um metro de comprimento, duas sacolas plásticas, laranjas e limões. Ainda que, do ponto de vista do equilíbrio, os materiais utilizados não sejam convencionais, eles possibilitam a aproximação do discurso instrucional, que se refere à noção de equivalência.

Figura 9 - Balança de equilíbrio de dois pratos não convencional

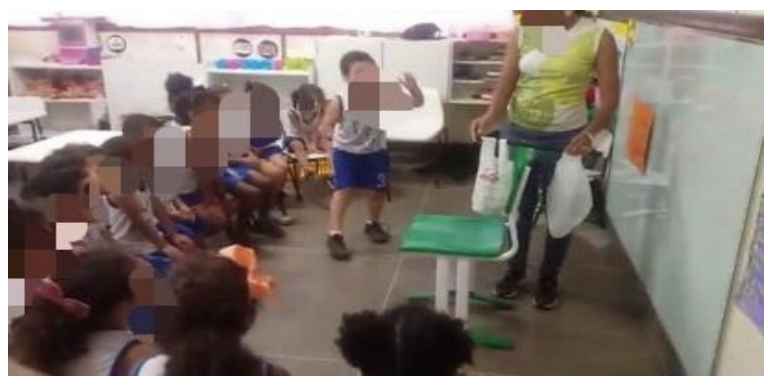

Fonte: Dados de pesquisa.

Como pode ser observado na Figura 9, as crianças estavam envolvidas, observando o equilíbrio entre as sacolas, embora os materiais utilizados não possibilitassem a exatidão do equilíbrio. Isso porque o ponto de equilíbrio da vara não é fixo no encosto da cadeira mas, observando o uso dos materiais por outro lado, é possível afirmar que esses, visualmente, permitiram que as crianças observassem o equilíbrio da vara no encosto da cadeira. Para que possamos analisar essa situação, trouxemos alguns excertos da aula ministrada. 
[PJ06] Prof. a Juliana: [...] Nós temos que conseguir equilibrar esse pau na cadeira. Será que se eu colocar ele aqui na cadeira ele fica? Vai ficar?

[CS07] Crianças: Não!

[C1008] Criança 10: Se você colocar parado aqui e aqui pode dar (A criança foi até a cadeira onde a professora estava tentando equilibrar a vara de madeira e tentou ajudá-la mostrar como ela podia conseguir equilibrar.)

$[\ldots]$

[PJ10] Prof. a Juliana: Precisa ter um peso aqui igual ao peso daqui. Certo? Olha eu trouxe uma laranja! [...] Vou colocar a laranja aqui dentro (Se referindo a sacola que estava do lado esquerdo da vara de madeira, depois olhou para a sacola que estava do lado direito da vara e questionou se existia alguma coisa dentro dela. As crianças disseram que não.).

[PJ11] Prof. a Juliana: Eu agora vou colocar aqui, será que vai equilibrar? Vocês acham?

[CS12] Crianças: Não!

[PJ13] Prof. Juliana: Porque não?

[C1014] Criança 10: Porque vai ficar pesado e vai cair, um lado com tanto peso.

$[\ldots]$

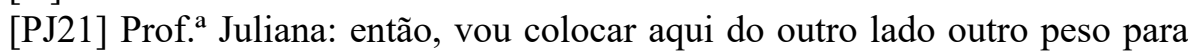
ver se a gente consegue equilibrar. Vou colocar um limão, será que equilibra com um limão?

[CS22] Crianças: Não! (Falaram baixinho com clima de dúvida.)

[C223] Criança 2: Pequeno demais!

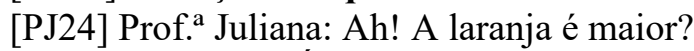

[C225] Criança 2: É!

$[\ldots]$

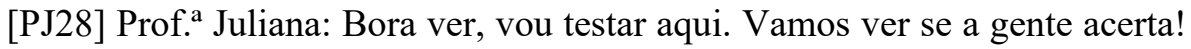
Oh! Oh! (Não equilibrou.)

[CS29] Crianças: Não! (Começaram a pular e a gritar pois as hipóteses deles estavam corretas.)

[PJ30] Prof. a Juliana: Com três limões agora, será que equilibra? Será? (Apontou para as sacolas, a que continha os três limões e a que continha a laranja.)

$[\ldots]$

[PJ33] Prof.a Juliana: vamos tentar com mais um limão! E agora será que a gente consegue equilibrar? (A professora colocou a vara de madeira no encosto, se afastou da cadeira e as sacolas equilibraram-se.)

[CS34] Crianças: Oba! Deu certo! (Todos ficaram muito felizes, gritando e batendo palmas.)

[PJ35] Prof. Juliana: Agora me digam uma coisa, para equilibrar aqui, foram quantas laranjas? Quantas laranjas eu coloquei aqui?

[CS36] Crianças: Uma!

[PJ37] Prof. a Juliana: Uma. Quantos limões?

[CS38] Crianças: Quatro!

[PJ39] Prof. ${ }^{a}$ Juliana: Ah! Então, uma laranja é igual a quantos limões?

[CS40] Crianças: Quatro!

[PJ41] Prof. a Juliana: Quantos limões eu coloquei? Bora contar? (Foi retirando os limões da sacola e contando com as crianças.)

A partir dos textos produzidos na prática pedagógica, na relação estabelecida entre a Professora Juliana e as crianças, é possível observar pontos relevantes. Os termos equilibra e equilibrar são produzidos pela professora, no entanto, nos textos das crianças esses termos não 
aparecem literalmente. Contudo, a noção do equilíbrio é expressada pelas crianças de diferentes formas (C1008, C1014, C223).

O fato de os termos não terem sido utilizados pelas crianças está associado aos tipos de questionamentos feitos pela professora, de tal forma que a resposta será, necessariamente, positiva (sim, é) ou negativa (não). Houve também resposta argumentativa, ainda que curta (C223), e um questionamento da professora, que suscita a explanação da criança (PJ13 e C1014).

No que diz respeito ao texto PJ39, este não é legítimo, pois, segundo Carpenter, Franke e Levi (2003), a igualdade deve ser usada tão somente para expressões numéricas. Desse modo, numericamente ficaria $1=4$, o que não procede, uma vez que o equilíbrio das frutas, em questão, se deu pela massa e não pela quantidade, pois trata-se de quantidades contínuas e não quantidades discretas. O registro da medida de massa não foi revelado, pois o material manipulativo que a professora utilizou na aula não permitia tal medição. Nessa situação seria legitimado, por exemplo, o seguinte texto: "o peso de uma laranja corresponde ao peso de quantos limões?".

Outro ponto a ser destacado é a utilização das sacolas que não eram transparentes e, para essa faixa etária, a visualização é fator relevante para que as crianças possam analisar a situação. Mesmo que as crianças tenham revelado a quantidade correta de laranjas e limões, a professora precisou tirar todas as frutas de dentro de cada uma das sacolas e contá-las.

Na segunda situação proposta pela Professora Juliana, ela levou para a aula uma caixa com diferentes materiais e foi aos poucos mostrando tudo às crianças. Retirou da caixa uma balança em miniatura e algumas frutas e começou a conversar com as crianças sobre a possibilidade de equilibrar o peso desses alimentos. Assim, juntos, sentados em uma rodinha, colocaram um morango do lado esquerdo da balança e quatro uvas do outro, como pode ser observado no diálogo abaixo:

[PJ42] Prof. a Juliana: Olha, se a gente tem aqui um morango igual a quatro uvas, ficou igual? Equilibrou?

[CS43] Crianças: Equilibrou!

A partir dos textos produzidos na prática pedagógica dessa segunda situação, na relação estabelecida entre a Professora Juliana e as crianças, observamos pontos que merecem destaque. Logo no início dos discursos (PJ42; CS43) já aparece o termo equilibrou produzido pela professora e pelas crianças. Esse dado é relevante, se compararmos com a situação 1, recém analisada, na qual esse termo não apareceu literalmente. 
Figura 10 - Balança de equilíbrio de dois pratos convencional

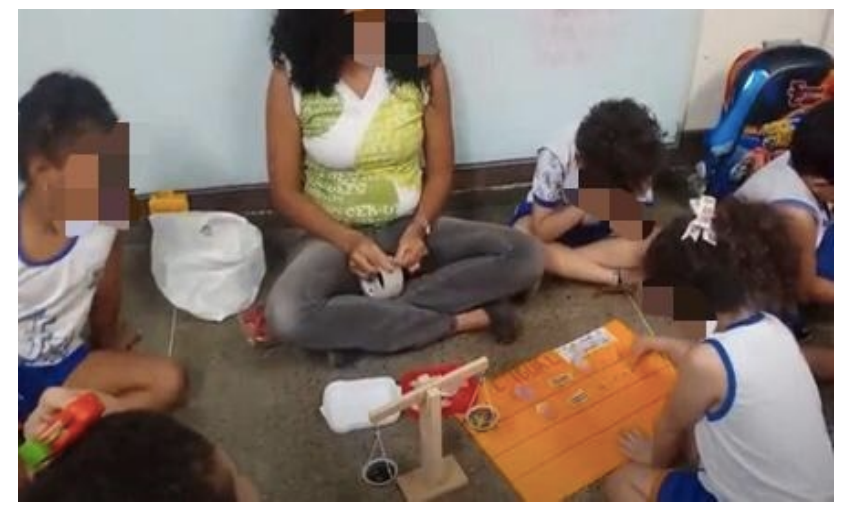

Fonte: Dados da pesquisa

A partir da Figura 10, constatamos que a professora aponta para o cartaz no chão e solicita que as crianças façam um registro das imagens que represente a igualdade entre um morango e quatro uvas. A proposta não tinha o objetivo de enfatizar a formalização: a medida em que as crianças construíam a ideia, a professora, junto com a participação delas, registrava no cartaz a relação entre os dois membros da igualdade.

A respeito desse tipo de registro, ele deve ser evitado como enfatiza Carpenter, Franke e Levi (2003, p. 20). É importante salientar que uvas não são iguais a morango e, segundo os autores, a igualdade só pode ser utilizada em registros numéricos. Além disso, ressaltamos que não faz sentido escrever $1=4$. Nessa atividade, os pesos das frutas que são equivalentes e, portanto, o registro legítimo deveria ser: "O peso de 1 morango é equivalente ao peso de 4 uvas".

[PJ44] Prof. a Juliana: Se eu colocar aqui outro morango!

[C845] Criança 8: Não, não, não! (A criança não queria que a balança desequilibrasse.)

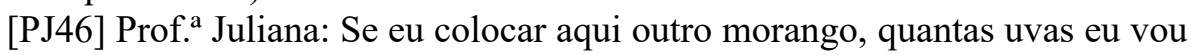
precisar aqui para equilibrar novamente?

[C447] Criança 4: sete!

[PJ48] Prof. ${ }^{\text {a Juliana: Será que é sete? }}$

[C449] Criança 4: não, é quatro!

[C350] Criança 3: mais quatro!

[PJ51] Prof. Juliana: Será que é quatro Ananda? Será que é mais quatro Lisa?

[C852] Criança 8: É oito!

[PJ53] Prof. ' Juliana: Vão precisar de quantas Antônio? É oito? Oito?

[C854] Criança 8: Oito!

[PJ55] Prof. Juliana: Se eu colocar mais quatro uvas aqui, será que fica?

Vamos ver? Mais uma uva, mais duas, mais três (...) (Na terceira uva que a professora acrescentou na balança ela parou, não colocou quatro uvas como as crianças haviam sugerido, pois a balança equilibrou) Equilibrou?

[CS56] Crianças: Equilibrou!

[PJ57] Prof. . Juliana: vamos contar quantas uvas tem aqui? Uma, duas, três, quatro, cinco, seis, sete.

[C58] Crianças: Sete!

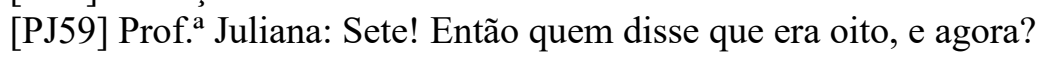


[C860] Criança 8: Eu disse que era sete, eu disse que era oito, depois.

[PJ61] Prof. Juliana: E agora? Porque será que ficou sete? (As crianças começaram a levantar hipóteses, todas falando ao mesmo tempo, então a professora retoma com outros questionamentos.)

[PJ62] Prof. a Juliana: E esse morango é igual a esse? O tamanho é igual? (As crianças dividiram opinião, algumas achavam que sim e outras falavam que não) Qual é mais pesado? (Continuou questionando a professora, apontando para o morango com o tamanho maior) Esse aqui, não é? Foi por isso que os pesos ficaram diferentes. Foram quantas uvas para dois morangos? [CS63] Crianças: Sete uvas e dois morangos. (Algumas crianças responderam)

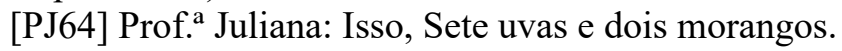

Ao continuar a equilibrar o peso das frutas, a professora acrescentou mais um morango e questionou qual seria a quantidade de uvas que ela deveria colocar do outro lado para equilibrar a balança. As crianças responderam que seriam mais quatro uvas, apresentando um texto legítimo do ponto de vista do princípio aditivo da igualdade, pois, se um morango equivale a quatro uvas, o peso de dois morangos equivale a oito uvas. Porém, quando foram verificar, a balança já equilibrou quando a professora acrescentou três uvas, totalizando sete. Se, por um lado, é importante trabalhar com a realidade das crianças, por outro lado é preciso escolher o tipo de material e o que se pretende desenvolver com ele.

As frutas naturais, sejam elas quais forem, nem sempre apresentam exatamente a mesma massa e, portanto, o princípio aditivo da igualdade pode não ser atendido. A relação entre as frutas está centrada na quantidade contínua (massa) e não na quantidade discreta (unidade). Para evitar a desconstrução do princípio aditivo da igualdade, em atividade desse tipo, é pertinente utilizar objetos que mantenham a mesma massa e, desse modo, é possível trabalhar com quantidades discretas. Uma sugestão seria trabalhar com moedas, botões, materiais cujas massas sejam equivalentes entre si e, por serem uniformes, o princípio aditivo da igualdade irá manter-se.

Ao analisarmos os textos produzidos (PJ46; C449; C350), do ponto de vista do raciocínio algébrico, pudemos observar que propostas como essa fomentam discussões que possibilitam trabalhar a aritmética generalizada. Os textos produzidos pelas crianças apontam que elas já são capazes de estabelecer relações e compreender a igualdade como uma relação entre as quantidades (BLANTON; KAPUT, 2005).

\section{Considerações Finais}

Retomando o objetivo desse estudo, que foi o de analisar os textos do discurso instrucional de igualdade que foram operados por uma professora no processo de 
recontextualização do curso de formação continuada em Early Algebra na sua sala de aula da educação infantil, vamos pontuar os principais resultados encontrados.

Nos dois processos de recontextualização da professora Juliana que foram analisados, foi possível observar que ela deslocou para sua sala de aula textos legítimos. Nas duas situações ela trabalhou com o texto do discurso da equivalência e apresentou os termos equilibrio, equilibrar, equilibrado, que é relevante se levarmos em conta que esses termos não somente são adequados, mas também são tidos como cernes da ideia de equivalência. Quanto ao texto do discurso das crianças, na segunda situação, elas, que já haviam externado a noção de equilíbrio na primeira situação, agora o fazem utilizando os mesmos termos ditos pela professora.

No desenvolvimento da aula a professora criou oportunidades para que as crianças visualizassem todo o procedimento nas duas situações, com o uso do material manipulável, envolvendo o contexto da balança. Nesses dois momentos foi nítido o envolvimento das crianças no desenrolar das atividades, mediante as interações e brincadeiras.

A professora Juliana trouxe para sua sala de aula materiais manipulativos pertinentes ao discurso instrucional da igualdade, no entanto, acompanhados de alguns textos não legitimados. Ao se reportar à relação de igualdade, ela o fez de forma equivocada, uma vez que a utilização do sinal de igualdade é restrito ao campo numérico. Além disso, apesar de ter priorizado materiais manipulativos em detrimento ao papel e lápis apenas, toda a manipulação foi centralizada na professora.

Outro aspecto que podemos apontar é que, no âmago de trazer para sala de aula o contexto da criança, a professora trabalhou com frutas naturais. Por considerar as frutas como sendo quantidades discretas, isso inviabilizou o princípio aditivo da igualdade. As frutas naturais nem sempre apresentam a mesma massa, desse modo quando tratadas como quantidades discretas, ao dobrar a quantidade de frutas de um prato da balança o resultado pode não ser compatível na mesma proporção da quantidade do outro prato.

Considerando os avanços nas produções das crianças os resultados desse estudo evidenciam que é possível trabalhar com noções de equivalência desde a educação infantil. Esta professora favoreceu que suas crianças, por meio das intervenções e da interação, conseguissem se aproximar de textos referentes ao discurso da igualdade.

Para finalizar, entendemos que as professoras não devem apenas se aproximar dos textos do discurso da igualdade, mas se apropriar deles, organizando de forma autônoma situações favoráveis ao processo de ensino e aprendizagem de conceitos concernentes a Early Algebra. No caso da professora desta pesquisa podemos perceber que a formação é um processo que 
demanda tempo e diferentes experiências e retomadas em relação ao tema em estudo. Para tanto, é necessário que haja mais pesquisas que promovam mais momentos formativos, de forma dialética, entre a teoria e a prática de sala de aula.

\section{Referências}

BEHR, M.; ERLWANGER, S.; NICHOLS, E. How children view the equal sign. Mathematics Teaching, n. 92, p. 13-18, 1980.

BERNSTEIN, B. Pedagogy, symbolic control and identity: theory research Critique. Revised Edition. London: Taylor and Francis, 2000.

BERNSTEIN, B. Class, codes and Control, Vol. IV: The structuring of pedagogic discourse. Londres: Routledge, 2003.

BLANTON, M.; KAPUT, J. J. Characterizing a classroom practice that promotes algebraic reasoning. Journal for Research in Mathematics Education, v. 36, n. 5, p. 412-446, 2005.

BRASIL. Ministério da Educação. Secretária de Educação Básica. Diretoria de Currículos e Educação Integral. Diretrizes Curriculares Nacionais Gerais da Educação Básica. Brasília: MEC, SEB, DICEI, 2013.

BRASIL. Ministério da Educação. Base Nacional Comum Curricular. 2017. Disponível em: $<$ http://basenacionalcomum.mec.gov.br/imagens/BNCCpublicacao.pdf $>$. Acesso em: 02 set. 2019.

CARPENTER, T. P.; LEVI, L.; FRANKE, M. L.; ZERINGUE, J. K. Algebra in Elementary School: Developing Relational Thinking. ZDM: The International Journal on Mathematics Education. DOI: 10.1007/BF02655897, February, 2005. Disponível em:

https://www.researchgate.net/publication/227006808 Acesso em: 26 out. 2020.

CARPENTER, T. P.; FRANKE, M. L.; LEVI, L. Thinking mathematically: Integrating arithmetic and algebra in elementary school. Portsmouth, NH: Heeinemann, 2003, 146p.

CRESWELL, J. Qualitative in query and research design: choosing among five traditions. Thousand Oaks: Sage Publications, 1998, 403p.

DENZIN, N. K.; LINCOLN, Y. S. O Planejamento da Pesquisa Qualitativa: teorias e abordagens. Porto Alegre: Artmed, 2006.

FERREIRA, Ângela Ateone Batista do Carmo. Formação híbrida de professores em Early Algebra na Educação Infantil: um olhar para os processos de recontextualização. 2020. 189f. Dissertação (Mestrado) - Programa de Pós-Graduação em Educação, Universidade Estadual de Feira de Santana, 2020. 
FERREIRA, M. C. N.; RIBEIRO, A. J.; PONTE, J. P. P. Prática profissional de professores dos anos iniciais e o pensamento algébrico: contribuições a partir de uma formação continuada. Educ. Matem. Pesq., São Paulo, v. 23, n. 1, p. 171-200, 2021.

LESSA, M. M. L. Balança de dois pratos e problemas verbais como ambientes didáticos para iniciação à Álgebra: um estudo comparativo. 1996. 236f. Dissertação (Mestrado em Psicologia) - Universidade Federal de Pernambuco, UFPE, Recife, 1996.

LUNA, A. V. A. A modelagem na formação continuada e a recontextualização pedagógica desse ambiente em salas de aula. 2012. Tese (Doutorado) - Programa de Pós-Graduação em Ensino, Filosofia e História das Ciências, Universidade Federal da Bahia, Salvador, 2012.

LUNA, A. V. A; BARBOSA, J. C.; MORGAN, C. Mathematical Modelling and Pedagogical Recontextualization of In-Service Teachers, 15. In: INTERNACIONAL CONFERENCE ON THE TEACHING OF MATHEMATICAL MODELLING AND APPLICATIONS - ICTMA, 15., 2011, Australian. Anais... Australian: Australian Catholic University, 2011. 1 CD-ROM.

LUNA, A. V. A.; MERLINI, V. L.; SILVA, V. N. Uma reflexão de textos elaborados por professoras da educação infantil sobre Early Algebra. EM TEIA - Revista de Educação Matemática e Tecnológica Iberoamericana, Recife, v. 11, n. 3, p. 1-24, 2020.

LUNA, A. V. A.; SOUZA, C. C. C. F. Discussões sobre o ensino de álgebra nos anos iniciais do ensino fundamental. Educação Matemática Pesquisa, São Paulo, v. 15, número especial, p. 817-835, 2013.

LUNA, A. V. A.; SOUZA, E. G.; SOUZA, C. C. C. F. Caminhos discursivos multimodais na aprendizagem da álgebra no primeiro ano do Ensino Fundamental. In: BORBA, R.; GUIMARÃES, G. (org.). Pesquisa e atividades para o aprendizado matemático na educação infantil e nos anos iniciais do ensino fundamental [livro eletrônico]. Brasília: Sociedade Brasileira de Educação Matemática - SBEM, 2015.

MERLINI, V. L.; MAGINA, S.; TEIXEIRA, C. O que sabem sobre equação, em representação icônica, os que formalmente ainda não sabem? VII SIPEM - SEMINÁRIO INTERNACIONAL DE PESQUISA EM EDUCAÇÃO MATEMÁTICA, 2018, Foz do Iguaçu. Anais... Foz do Iguaçu. 2018. p. 1-12.

NATIONAL COUNCIL FOR TEACHER OF MATHEMAIS/ NCTM. Princípios e Normas para a Matemática Escolar. Trabalho original publicado em 2000. Tradução da Associação de Professores de Matemática (APM). Lisboa: Associação de Professores de Matemática e Instituto de Inovação Educacional, 2007.

PONTE, J. P.; BRANCO, N.; MATOS, A. Álgebra no ensino básico. Lisboa: MEDGIDC, 2009.

SCHLIEMANN, A. D.; CARRAHER, D. W.; BRIZUELA, B. EI carácter algebraico de la aritmética: de las ideas de los niños a las actividades en el aula. Buenos Aires: Paidos, 2011. 
STACEY, K.; MACGREGOR, M. Ideas about symbolism that students bring to algebra. The Mathematics Teacher. National Council of Teachers of Mathematics. 1997, p. 110-113.

TOLEDO, M. Didática da Matemática: como dois e dois: a construção da matemática. São Paulo: FTD, 1997.

VIEIRA, F.; MAGINA, S.; LUNA, A. V. Formação inicial do raciocínio funcional na Educação Infantil. Revista de Ensino de Ciências e Matemática, São Paulo, v. 12, n. 3, p. 120, 6 jun. 2021. 